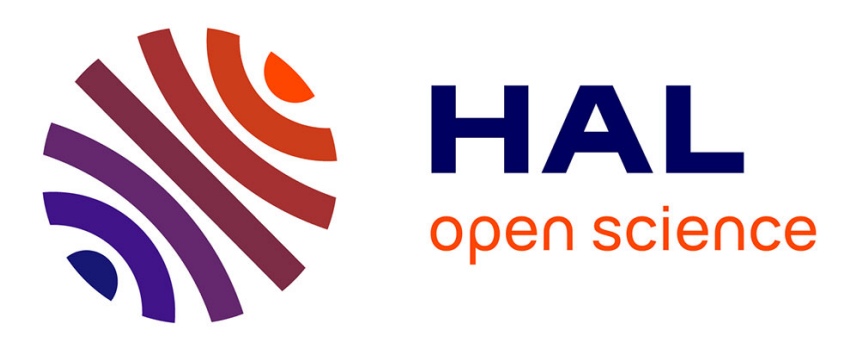

\title{
Geometric descriptors of road surface texture in relation to tire/road noise
}

\author{
Fabienne Anfosso, Minh Tan Do
}

\section{To cite this version:}

Fabienne Anfosso, Minh Tan Do. Geometric descriptors of road surface texture in relation to tire/road noise. Transportation Research Record, 2002, 1806, pp. 160-167. 10.3141/1806-18 . hal-00851385

\section{HAL Id: hal-00851385 \\ https://hal.science/hal-00851385}

Submitted on 13 Aug 2013

HAL is a multi-disciplinary open access archive for the deposit and dissemination of scientific research documents, whether they are published or not. The documents may come from teaching and research institutions in France or abroad, or from public or private research centers.
L'archive ouverte pluridisciplinaire HAL, est destinée au dépôt et à la diffusion de documents scientifiques de niveau recherche, publiés ou non, émanant des établissements d'enseignement et de recherche français ou étrangers, des laboratoires publics ou privés. 


\section{Geometric Descriptors of Road Surface Texture in Relation to Tire/Road Noise}

Fabienne Anfosso-Lédée

LCPC - Route de Bouaye - BP 4129 - 44341 Bouguenais - FRANCE

Phone : +33240845792

Fax : + 33240845992

E-mail : fabienne.anfosso@lcpc.fr

Minh-Tan Do (Corresponding author)

LCPC - Route de Bouaye - BP 4129 - 44341 Bouguenais - FRANCE

Phone : +33240845795

Fax : + 33240845992

E-mail : $\underline{\text { minh-tan.do@1cpc.fr }}$

WORD COUNT : 7376 WORDS 


\begin{abstract}
The paper deals with the determination of geometric parameters in order to study the relationship between the tire/road noise and the texture of road surfaces. The approach was found to be an alternative to the classical spectral analyses and the numerical simulations of the tire/road contact. Texture parameters were derived from previous works in LCPC related to the influence of the microtexture of road surfaces on the skid resistance. Use of these parameters was justified by the consideration of generation mechanisms of rolling noise. Texture, rolling noise and absorption measurements were performed on 12 road surfaces. The measuring devices and the test methods were presented. The texture profile analyses, including the spectral and geometric approaches, were presented. Definitions of the geometric parameters were given. Correlation between the noise and texture spectra showed similar results to those published in previous works. Fair tendencies were found between the global noise level at $90 \mathrm{~km} / \mathrm{h}$ and the geometric parameters. Unexpected results obtained on the porous asphalt surfaces were partially explained by the attenuation effect, which was quantified by using existing models. Results issued from the correlation between the third octave-band noise levels and the geometric parameters corroborated those of the spectral analyses.
\end{abstract}

\title{
INTRODUCTION
}

The noise generated by tire/road contact is the major contribution to light vehicle noise emission at typical cruising speeds, and consequently produces a considerable nuisance in the environment. The physical phenomena generating this noise are both vibratory and aerodynamic. The vibratory mechanisms are responsible for low frequency emission $(<1 \mathrm{kHz})$. They come from the tire deformation during the contact with the pavement surface, and from the impact between the rubber treads and the surface. The aerodynamic mechanisms are responsible for high frequency emission $(>1 \mathrm{kHz})$. They correspond to the successive compression/relaxation cycles of the air trapped inside the contact patch, called "air pumping". Both tire and road surface parameters influence the noise emitted. The main parameters of road pavements regarding noise are texture and porosity. Rough texture increases the tire vibration and consequently increases its sound radiation. Air pumping effect is maximum on a smooth pavement, but highly reduced by porosity. In the seventies, Sandberg and Descornet (1) established correlation relations between tire/road noise spectrum (sound pressure level as a function of temporal frequency) and road texture spectrum (height of the texture profile as a function of spatial wavelength), on an experimental basis. They identified two zones corresponding respectively to both generating mechanisms: one in low frequency range (below $1.5 \mathrm{kHz}$ ) of positive correlation related to radial vibration of the tire, the second in high frequency range of negative correlation related to air pumping effect.

Some more recent researches on the subject, used sophisticated numerical codes (Finite Element Method, Boundary Element Method...) to develop comprehensive models for tire noise prediction where the input data were 2D (2) or 3D (3) texture profiles. By use of mechanical contact model, the enveloped texture profile is transformed into surface displacement or strain at the contact patch, and the resulting vibration and radiation of the tire were derived after significant calculation with structural dynamic models.

In this paper, a simple and comprehensive characterization of texture profiles is proposed in relation to tire/road noise. The final aim is to define relevant geometric descriptors in order to assess the relationship between the road surface texture and the rolling noise.

\section{RESEARCH METHODOLOGY}

Recently, LCPC developed a profile analysis method to characterize the geometry of microtexture asperities by means of two angular parameters and relate it to the skid resistance (4)(5). The microtexture is defined as surface asperities which height ranges from $0.001 \mathrm{~mm}$ to $0.5 \mathrm{~mm}$ and width is less than $0.5 \mathrm{~mm}(6)$. These asperities are required mainly under wet conditions to breakdown the thin water film and to enhance the creation of effective areas of contact with the tire treads. The angular parameters are related to the shape and relief of the indenters, which were defined as asperities in contact with the tire. Results obtained on road surfaces showed fair correlation between the two angular parameters and the low speed friction (5).

It was proposed to use the shape and relief parameters as descriptors of the macrotexture of road surfaces and relate it to the rolling noise. The macrotexture is defined as surface asperities that range from $0.1 \mathrm{~mm}$ to $20 \mathrm{~mm}$ in height and from $0.5 \mathrm{~mm}$ to $50 \mathrm{~mm}$ in width (6). The idea is supported by the similarities between the generation mechanisms of friction and rolling noise, both taking into account the deformation of the tire by the 
road surface irregularities. The objective was to validate the relevance of the descriptors by correlation with noise levels.

Parallel with the geometric analyses, a spectral analysis was performed. The aim was to check if former results of spectral correlation in (1) were still valid for current road surfaces and tires.

\section{EXPERIMENTAL PROGRAM}

\section{Test Sites}

Tests were performed on 12 road surfaces located on the test tracks of LCPC and INRETS. The surfaces were composed of (the maximum aggregate size in millimeter is indicated in brackets):

- 2 dense asphalt concrete $(10 \mathrm{~mm})$;

- 4 surface dressing (1.5mm, $4 \mathrm{~mm}, 10 \mathrm{~mm}$ and $14 \mathrm{~mm})$;

- 2 porous asphalt concrete $(10 \mathrm{~mm})$;

- 1 porous cement concrete $(10 \mathrm{~mm})$;

- 1 very thin asphalt concrete $(10 \mathrm{~mm})$;

- 1 cement concrete;

- 1 smooth epoxy surface.

\section{Tire/Road Noise Measurements}

A controlled pass-by method (CPB) was chosen for noise evaluation, according to the standard procedure (7). In this method, the pass-by noise of a vehicle driven at a constrained speed is measured at a $7.5 \mathrm{~m}$ distance from the vehicle path and $1.2 \mathrm{~m}$ above the ground. One small and new passenger car was used, fitted successively with two different tire sets, one rather noisy (large and stiff rubber) and one rather quiet (narrow and soft rubber). Each measurement consisted in eight runs per tire configuration, homogeneously distributed over the total speed range (from $70 \mathrm{~km} / \mathrm{h}$ to $110 \mathrm{~km} / \mathrm{h}$ ). Each run was characterized by the maximum pass-by noise level and the vehicle speed measured with a radar. Linear regression on the eight noise level - speed data points was performed and the tire/road noise level at the reference speed $90 \mathrm{~km} / \mathrm{h}$ was derived. The same analysis was done for each third octave frequency band ranging from $100 \mathrm{~Hz}$ to $5 \mathrm{kHz}$, to derive the noise third octave band spectrum at $90 \mathrm{~km} / \mathrm{h}$. The noise level and spectrum representative of the road pavement were taken as the average level between the two tire configurations. The global noise levels were used for geometric analysis, third octave band spectra were used for spectral analysis. This procedure is close to the one used by (1) when establishing the texture/noise relationship.

\section{Texture Measurements}

The texture measurements were done by means of a device developed at LCPC using a triangulation laser sensor. The spot diameter of the laser beam is $0.5 \mathrm{~mm}$. Sensor measuring range is $20 \mathrm{~mm}$ with vertical resolution less than $5 \mu \mathrm{m}$.

The profile positions are shown in the figure 1 . On each test surface, 20 profiles of 1 -meter length (L) were sampled every $0.05 \mathrm{~mm}$ along the wheel tracks. They were divided into two series of 10 profiles for each wheel track. The space between the individual profiles was 2 meters.

On each profile, invalid points (dropouts) were first suppressed and replaced using the linear interpolation technique. The profile slope was then removed by means of the least squares method.

\section{ANALYSIS OF TEXTURE PROFILES}

\section{Spectral Analysis}

Each texture profile was signal processed in order to get the texture power spectrum. It means that by a Fourier transformation, the texture profile is expressed as a function of spatial wavelength. The profile level $L_{x}$ is expressed in $\mathrm{dB}$ according to the following : 


$$
L_{x}=20 \log _{10}\left(\frac{a_{x}}{a_{r e f}}\right)
$$

where $a_{x}$ : profile root mean square $(\mathrm{m})$

$a_{\text {ref }}\left(=10^{-6} \mathrm{~m}\right):$ reference root mean square value of the texture profile amplitude

$x$ : subscript indicating a value obtained with a certain filter

In the present case, third octave wavelength bands were considered. Texture spectral components were expressed in 21 third octave bands, ranging from center wavelength $250 \mathrm{~mm}$ to $2.5 \mathrm{~mm}$. This limits are related respectively to the length $(\mathrm{L})$ of the profile and to the spatial sampling of the measurement. The final texture spectrum representative of the road surface is obtained by averaging the spectra of the 20 profiles. A fuller description of the signal processing procedures can be found in (8).

The next step was to correlate the noise spectrum and the texture spectrum of the 12 pavements. Thus for each of the 18 noise third octave bands $\left(f_{i}\right)$ and each of the 21 texture bands $\left(\lambda_{j}\right)$, the noise level of the 12 pavements were plotted against the texture level. The regression line and the correlation coefficient was derived for each of the $18 \times 21$ couples $\left(f_{i}, \lambda_{j}\right)$. An illustration is presented in figure 2 corresponding to the noise frequency $630 \mathrm{~Hz}$ and the texture wavelength $160 \mathrm{~mm}$. Each dot corresponds to a pavement.

\section{Profile Analyses by Means of Geometric Parameters}

The concept of the shape and relief description was fully developed in previous papers (4)(5), only some brief definitions are given in this paper. The analysis method developed in LCPC focused on the significant features of the profiles, that is, the asperities called "indenters", which are in contact with the tire. Profile indenters were defined as being composed of a profile peak and its two neighboring left-right valleys (Fig. 3). The indenter shape was defined locally as the cotangent of its summit semi-angle $(\alpha)$. In order to take into account the relative positions of the indenters, the indenter relief was defined locally as the angle $(\theta)$ between the segment connecting the summits of two consecutive indenters and the horizontal.

Beside the angular parameters, it was also possible to define the density as being the number of indenters per unit length.

Peaks and valleys were defined as points respectively higher and lower than their neighboring left and right points. Formulae for calculating the shape and relief are the following:

$$
\theta=\tan ^{-1}\left|\frac{z_{p+1}-z_{p}}{x_{p+1}-x_{p}}\right|
$$

where $z_{p}, x_{p}$ : height and abscissa of the $p^{\text {th }}$ peak.

$$
\alpha=\frac{1}{2} \times\left[\tan ^{-1}\left|\frac{\mathrm{x}_{\mathrm{e}}-\mathrm{x}_{\mathrm{e}-1}}{\mathrm{z}_{\mathrm{e}}-\mathrm{z}_{\mathrm{e}-1}}\right|+\tan ^{-1}\left|\frac{\mathrm{x}_{\mathrm{e}+1}-\mathrm{x}_{\mathrm{e}}}{\mathrm{z}_{\mathrm{e}+1}-\mathrm{z}_{\mathrm{e}}}\right|\right]
$$

where $z_{e}, x_{e}$ : height and abscissa of the $e^{\text {th }}$ extremum.

. The profile analyses were performed by means of a MATLAB ${ }^{\circledR}$ program developed at LCPC. The profiles were re-sampled at a sampling interval of $0.5 \mathrm{~mm}$, meaning that the smallest indenter width that could be detected is $1 \mathrm{~mm}$. Option is given in the program to analyze only a part of the profiles. The analysis threshold is defined as a fraction of the difference between the maximum and the minimum amplitudes ( 0 : the whole profile is analyzed; 1: no part of the profile is analyzed). In this study, it was decided to use a threshold of 0.5 , meaning that only the upper half of the profiles were analyzed. This choice was supported by the fact that only the parts of the profile in contact with the tire are of interest and the troughs of the profiles might be neglected. 
Example of calculation result on actual profiles is shown in the figure 3. For the purpose of clarity, only part of the measured profile $(0.1 \mathrm{~m}$ length) was shown.

On each profile, the indenters were detected and the related shape and relief values were calculated. Values of cotangent $(\alpha)$ and $(\theta)$ from the 20 profiles measured on each test surface were then regrouped from which the respective mean values were calculated to characterize the macrotexture of the test surfaces. The density was also calculated by dividing the total number of indenters by the total profile length (20 meters).

\section{RESULTS}

\section{Spectral Correlation}

The final result of correlation between noise and texture spectra is summarized in figure 4 . This plot is a graphic representation of the $18 \times 21$ correlation coefficients obtained from the regression calculations between noise and texture levels in each third octave band, as described previously. The discrete values of coefficients are interpolated in order to get contours of iso-correlation.

This contour plot is similar to the one found in (1), where a positive correlation can be found for low noise frequencies and large texture wavelengths, and a negative correlation can be found for high noise frequencies and small texture wavelengths. However the correlation is better when the porous pavements are excluded from the statistical analysis (Fig. 5). This can be due to two particularities of porous pavements. First, the level of texture might be overestimated, because the calculation procedure (1) evaluates the negative texture (troughs corresponding to the entrance of the pores) as a positive one (peaks). Second, the sound level measured along the road underestimates the emitted noise level which is attenuated along the propagating path due to the acoustic absorption in the porous pavement.

\section{Correlation between Noise and Geometric Parameters}

The correlation between the global noise levels and the geometric parameters is shown in figures 6,7 and 8 for respectively the shape, the relief and the density.

General tendencies showed that the rolling noise increases when cotangent $(\alpha)$ or $(\theta)$ increases, or when the density decreases. Results related to the shape and relief seemed at a first glance to be logical, for shocks between the tire treads and the road surface asperities, which cause the vibration of the tires, should be amplified when the asperities are harsh or when their relative position creates pronounced relief. However, it should be mentioned that higher alpha (lower cotangent $(\alpha)$ ) means both decreased drainage capacity and decreased vibration excitation. The first effect increases noise due to air pumping for the tire rubber will envelop more the asperities. The second effect decreases noise at low frequencies due to decreased rubber deformation. For the two effects are contradictory, the observed results should depend strongly on the selected surfaces and tires. Higher theta would have a similar effect as described for alpha.

Results related to the density are more surprising, for one would expect higher noise levels when the number of indenters increases. However, higher density means smaller spacing between indentors, which should give lower vibration excitation as well as higher drainage capacity to eliminate air pressure. These two effects reduce global noise levels and should explain the relationship between noise and density.

Strong correlation was found between the three geometric descriptors. Values of the coefficient of correlation between cotangent $(\alpha)$ and $(\theta),(\theta)$ and density, density and cotangent $(\alpha)$ are respectively $r=0.96, r=-$ 0.82 and $\mathrm{r}=-0.86$. For the selected surfaces, the geometric descriptors might not be then treated as independent variables.

It was noted on each correlation that 4 points do not belong to the mean tendency: one point for which the expected rolling noise was lower than the measured value, and three points for which the expected rolling noise was higher than the measured value. Examination of the type of surface showed that the first point corresponds to a very rough surface dressing and the last three points correspond to the porous surfaces. The result obtained on the surface dressing should mean that significant asperities were missed in the calculations. Further investigation is needed to see if any relevant texture scale was neglected in the profile analysis procedure. The result obtained on the porous surfaces might be explained by the fact that the geometric 
parameters were defined to take into account only the deformation of the tire, and the attenuation aspect, which is essential on porous asphalt surfaces, was not considered. The noise levels obtained on the porous asphalt surfaces were then corrected by means of absorption measurement to suppress the attenuation effect.

\section{Attenuation Effect for Noise Propagation above Porous Surface}

Pass-by noise is reduced on porous road surfaces for two main reasons. First, the "air pumping" phenomenon is reduced: instead of being trapped between the tire and the pavement, the air evacuates through the pores. This results in a reduced noise emission. The second reason is due to sound absorption above the porous surface: the noise emitted is attenuated when propagating from the tire to the receiver along the road. This additional and independent effect, very significant at some frequencies, should not be taken into account when correlating road texture and noise emitted.

A correction for sound propagation was proposed. The frequency dependent attenuation of sound between the tire and the receiver was calculated with a model described in (9), both for reflecting (traditional pavement) and absorbing (porous pavement) conditions. The plane wave sound absorption coefficient of the three porous samples was measured and introduced in the propagation model. Each third octave band noise level can then be corrected by:

$$
\mathrm{L}_{\text {corrected }}=\mathrm{L}_{\text {measured }}+\left(\mathrm{L}_{\mathrm{ref}}-A t t\right)
$$

where $\mathrm{L}_{\text {ref }}$ : calculated sound level for purely reflecting propagation conditions, Att : calculated sound attenuation above the porous surface.

This correction was applied to the three porous pavements. The calculated attenuations based on absorption coefficient measurements on the three porous surfaces are presented in figure 9 . They correspond to a $4 \mathrm{~cm}$ high point source and a $1.20 \mathrm{~m}$ high receiver separated by a $7.50 \mathrm{~m}$ distance. The effect of this correction on the correlation procedure is illustrated in figure 10 for the third octave bands centered at frequency $2500 \mathrm{~Hz}$ and the wavelength $12.5 \mathrm{~mm}$. The three porous pavements were clearly responsible for a rather low correlation $(\mathrm{r}=-0.64)$. The noise level correction of sound attenuation plotted with round symbols, improved the correlation $(\mathrm{r}=-0.72)$, although it seems not sufficient to satisfactorily correlate texture and noise. The reduction in air pumping may be the additional effect that reduces noise levels. Finally, for all the spectral range, the corrected contour plot is shown in figure 11. Better correlation zones appear more clearly than in the initial plot (Fig.4).

The corrected noise levels of the porous surfaces are also shown in figures 6, 7 and 8 . Fairer tendency was obtained when considering the attenuation effect, the coefficient of correlation ( $r$ ) of the relationships being improved as shown in the table 1. It was then decided to use the corrected noise levels for porous surfaces in subsequent discussions.

\section{Comparison of Results Obtained by the Spectral and Geometric Analyses}

Results issued from spectral analyses commonly showed the noise frequencies and the texture wavelengths where highest correlation is obtained, and the noise frequency at which the sign of the texture - noise correlation is reversed.

Attempts were made to see how the geometric approach could corroborate the spectral approach. Analyses were performed on the shape parameter. Linear relationships between the 3rd octave band noise levels and the cotangent $(\alpha)$ values were determined by means of linear regressions. The regression constant values were reported in the table 2 . The correlation coefficients ( $r$ ) were then related to the noise frequencies. The graph is shown in figure 12. Use of (r) values instead of $r$-squared values was preferred for the sign of the correlation slopes is given also by the sign of the (r) values.

The (r) values were not very high, partly due to the presence of the two coarse surface dressing. The $r-$ frequency graph presented a maximum at $630 \mathrm{~Hz}$ and a minimum at $2000 \mathrm{~Hz}$, meaning that highest correlation was obtained at these two frequencies. It could be interesting to note that the slope sign was reversed at $1250 \mathrm{~Hz}$ 
(Fig. 12), which corresponded to the zero r-values. Sharp asperities tended to increase (respectively decrease) the rolling noise at frequencies lower (respectively higher) than $1250 \mathrm{~Hz}$.

Similarities might then be found between the results obtained from the geometric analyses and from the spectral analyses dealt with in this paper or in previous works (1). Indeed, both geometric and spectral analyses indicated the same noise frequencies at which respectively highest positive correlation was obtained $(630 \mathrm{~Hz})$ and the sign of the correlation slopes was reversed $(1250 \mathrm{~Hz})$. Analyses performed in (1) indicated the same order of frequency $(\approx 1500 \mathrm{~Hz}$ ), which separated the positive from the negative correlation.

\section{CONCLUSIONS}

In this paper, a geometric description of the road surfaces was proposed to relate the surface texture to the tire/road noise. The descriptors characterized the shape and relief of surface asperities, which are significant features in the tire/road contact. Fair correlation was found between the geometric parameters and the noise levels. Similar results were also found between the geometric analyses and the common spectral analyses. Correlation between noise level and texture level spectra confirmed good correlation zones, which were observed in previous studies, especially when porous pavements are excluded.

For porous surfaces, a method was successfully used to eliminate the extra attenuation in noise level spectra due to the propagation above a sound absorbing surface. This correction of noise level improved both geometric and spectral correlation derived for all types of pavement. But it is probably insufficient as porosity of the road surface also reduces noise emission due to air pumping, an effect that may not be related just to texture geometry, even deep texture.

Further investigations are needed to confirm these preliminary results. Particularly more data must be collected to improve the statistics of the analyses, for the number of test surfaces is a little low to provide statistically significant correlation. The texture profile analysis must be refined to take into account other relevant texture scales. It should be mentioned that the proposed approach is intended neither to replace nor to be an alternative of spectral analysis, which is a much more comprehensive approach. The geometric analysis might but be a simple way to investigate the texture-noise relationship, particularly to relate surface descriptors to formulation parameters.

\section{ACKNOWLEDGEMENTS}

The authors thank M. Lecerf, J. F. Le Fur, P. Marsac, Y. Pichaud and M. Roura from LCPC for their help.

\section{REFERENCES}

1. Sandberg, U. and G. Descornet. Road Surface Influence on Tire/Road Noise - Part 1. Proceedings of the 1980 International Conference on Noise Control Engineering (Inter-Noise 80), December $8^{\text {th }}-10^{\text {th }} 1980$, Miami, Florida, pp. 1-8.

2. Cenek, P.D., Fong, S., Jamieson, N.J., and M.W. McLarin. Integration of Road and Tyre Design-Overview of New Zealand Research. Proceedings of the $2^{\text {nd }}$ International Colloquium on Vehicle Tyre Road Interaction, February $23^{\text {rd }} 2001$, Florence, Italy, pp 411-427.

3. Domenichini, L., Fracassa, A., La Torre, F., Loprencipe, G., Ranzo, A., and A. Scalamandrè. Relationship between road surface characteristics and noise emission. Proceedings of the $1^{\text {st }}$ International Colloquium on Vehicle Tyre Road Interaction, May 1999, Rome, Italy.

4. Do, M. T., Zahouani, H., and R. Vargiolu. Angular Parameter for Characterizing Road Surface Microtexture. In Transportation Research Record 1723, TRB, National Research Council, Washington, D.C., 2000, pp. 66-72.

5. Zahouani, H., Vargiolu, R., and M. T. Do. Characterization of Microtexture Related to Wet Road/Tire Friction. Proceedings of the $4^{\text {th }}$ International Symposium on Pavement Surface Characteristics of Roads and Airfields, May $22^{\text {nd }}-24^{\text {th }} 2000$, Nantes, France, pp. 195-205.

6. ISO 13473-1. Characterization of Pavement Texture by Use of Surface Profiles - Part 1: Determination of Mean Profile Depth. 1997.

7. AFNOR NF S 31-119. Caractérisation in situ des qualités acoustiques des revêtements de chaussées. Mesurages acoustiques au passage - Procédure "Véhicules Maîtrisés". 1999. 
8. ISO/TC43/SC1/TS 13473-4. Characterization of Pavement Texture by Use of Surface Profiles - Part 4 : Spectral analysis of texture profile. (first working draft)

9. Bérengier, M., Stinson, M. R., Daigle, G.A. and J. F., Hamet. Porous Road Pavements : Acoustical Characterization and Propagation effects. Journal of Acoustical Society of America, Vol. 101, No. 1, 1997, pp. $155-162$ 


\section{FIGURE CAPTIONS}

FIGURE 1 Position of measured texture profiles.

FIGURE 2 An example of correlation between noise and texture third octave bands.

FIGURE 3 Definition of the geometric parameters.

FIGURE 4 Contour lines of correlation coefficient between noise level $(90 \mathrm{~km} / \mathrm{h})$ and texture level - all pavements.

FIGURE 5 Contour lines of correlation coefficient between noise level $(90 \mathrm{~km} / \mathrm{h})$ and texture level - porous pavement excluded.

FIGURE 6 Relationship between indenter shape and noise.

FIGURE 7 Relationship between indenter relief and noise.

FIGURE 8 Relationship between indenter density and noise.

FIGURE 9 Calculated sound attenuation above porous surfaces (bars) and reflecting surface (curve).

FIGURE 10 Correlation between noise and texture levels for third octave bands centered on frequency $2500 \mathrm{kHz}$ and wavelength $12.5 \mathrm{~mm}$.

FIGURE 11 Contour lines of correlation coefficient between noise level and texture level - attenuation correction for porous pavements.

FIGURE 12 Variation of the coefficient of correlation between noise and texture with noise frequency.

\section{TABLE TITLES}

TABLE 1 Correlation Between Global Noise Level and Geometric Descriptors

TABLE 2 Results from Linear Regression on Noise $3^{\text {rd }}$ Octave Band Levels and Cotangent $(\alpha)$ Values 


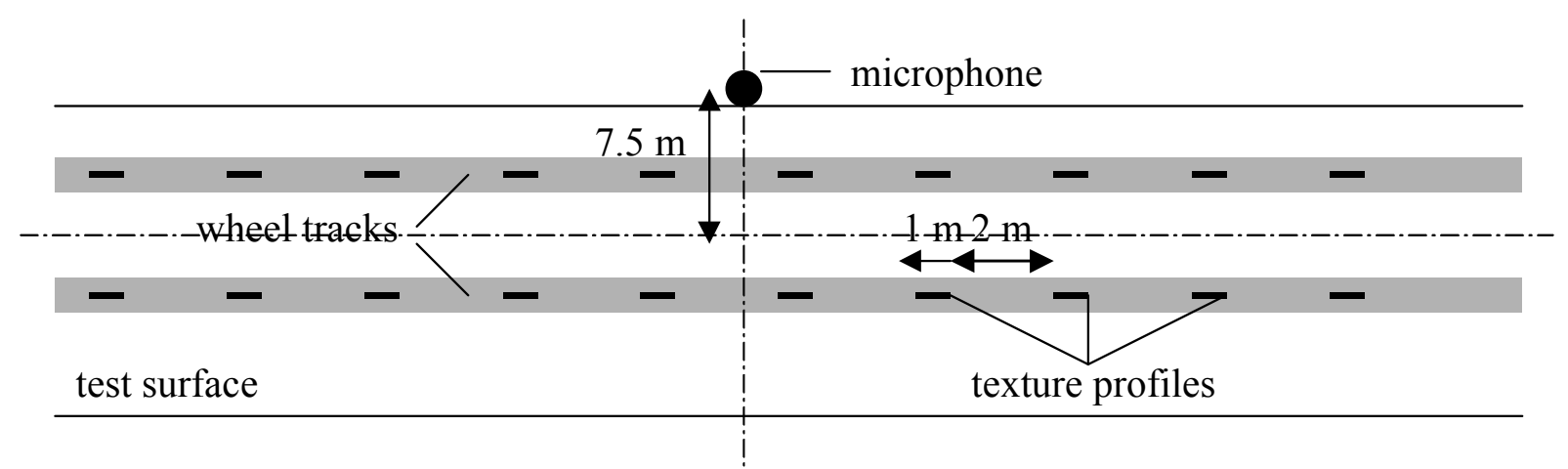

FIGURE 1 Position of measured texture profiles. 


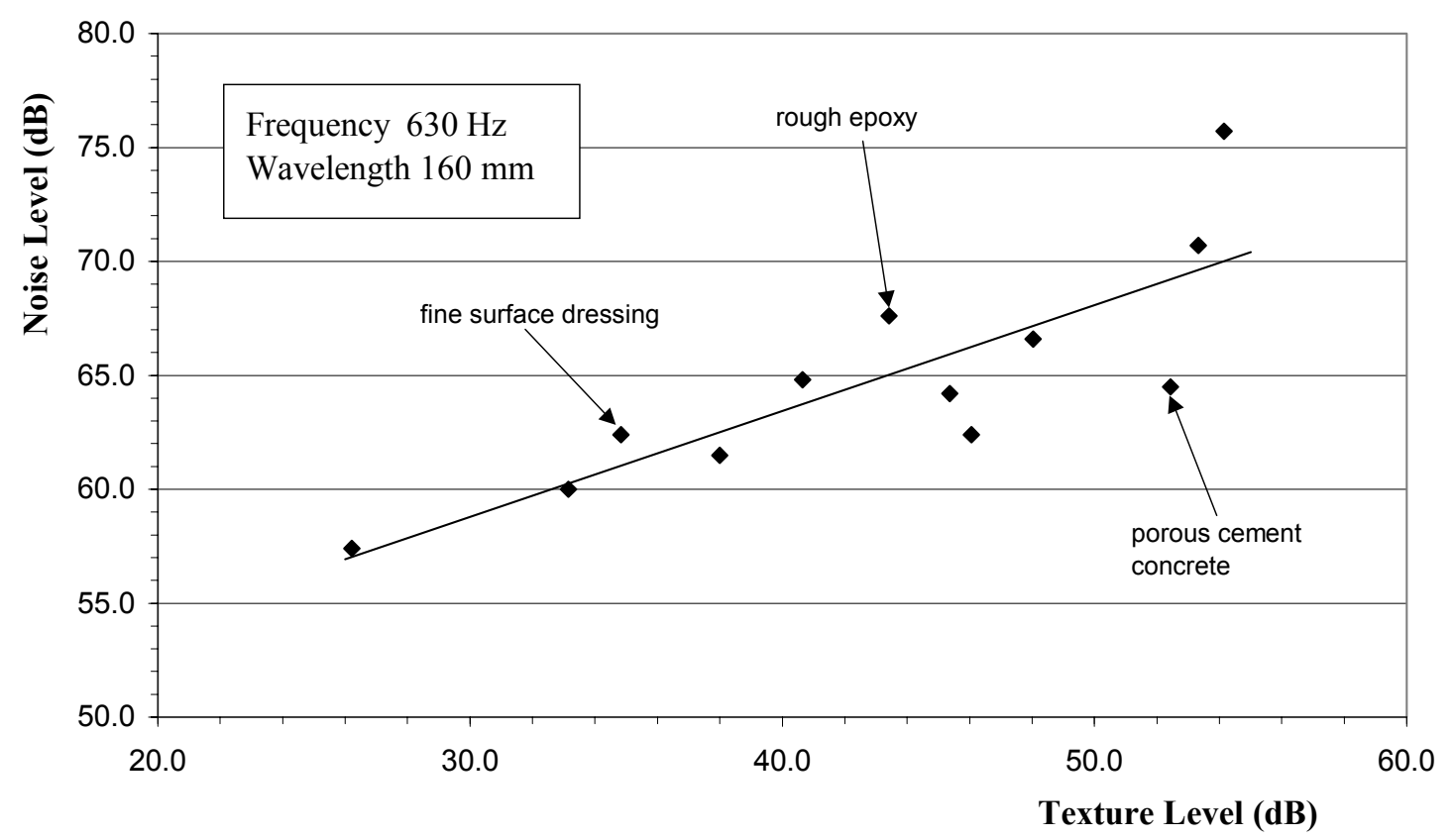

FIGURE 2 An example of correlation between noise and texture third octave bands. 


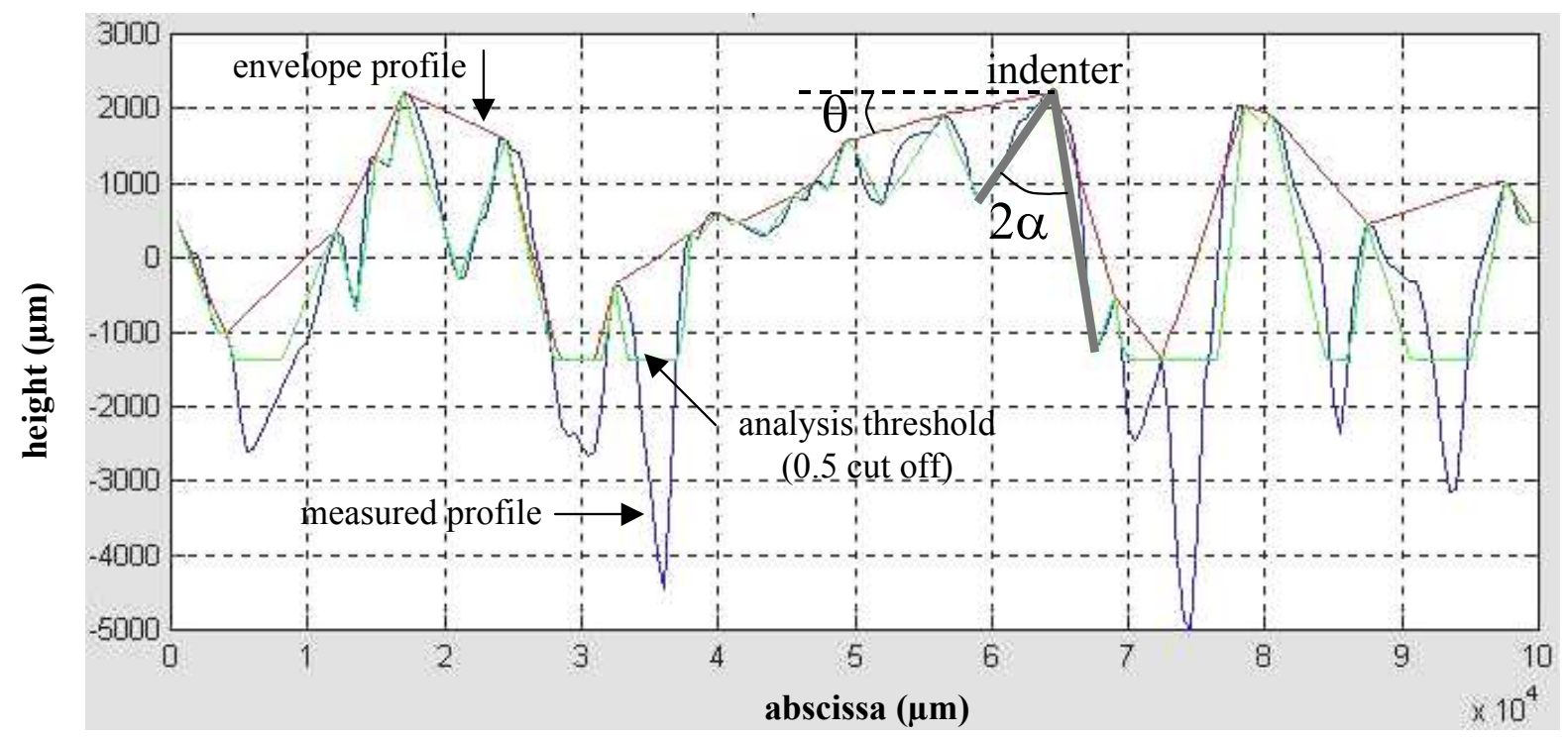

FIGURE 3 Definition of the geometric parameters. 


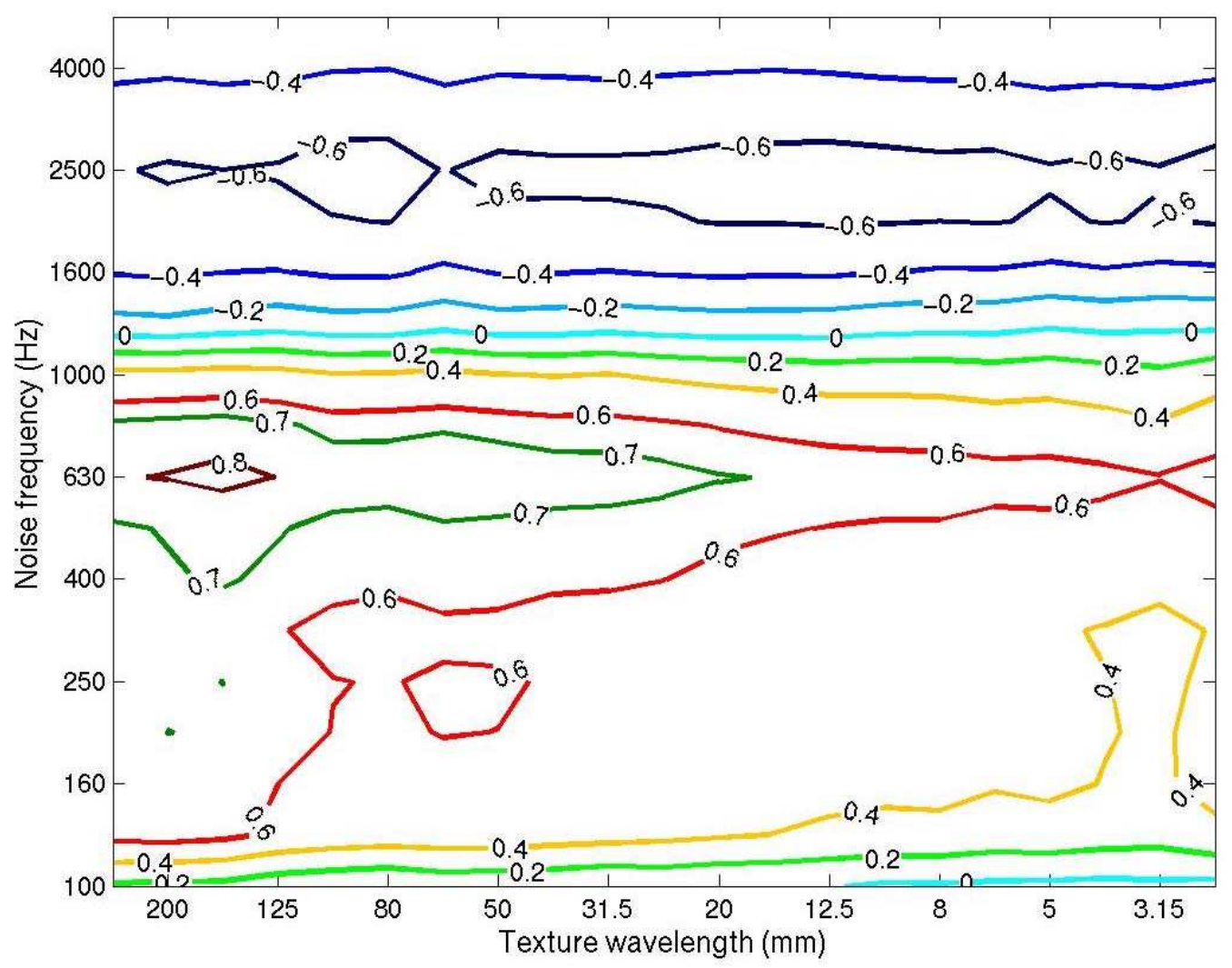

FIGURE 4 Contour lines of correlation coefficient between noise level $(90 \mathrm{~km} / \mathrm{h})$ and texture level - all pavements. 


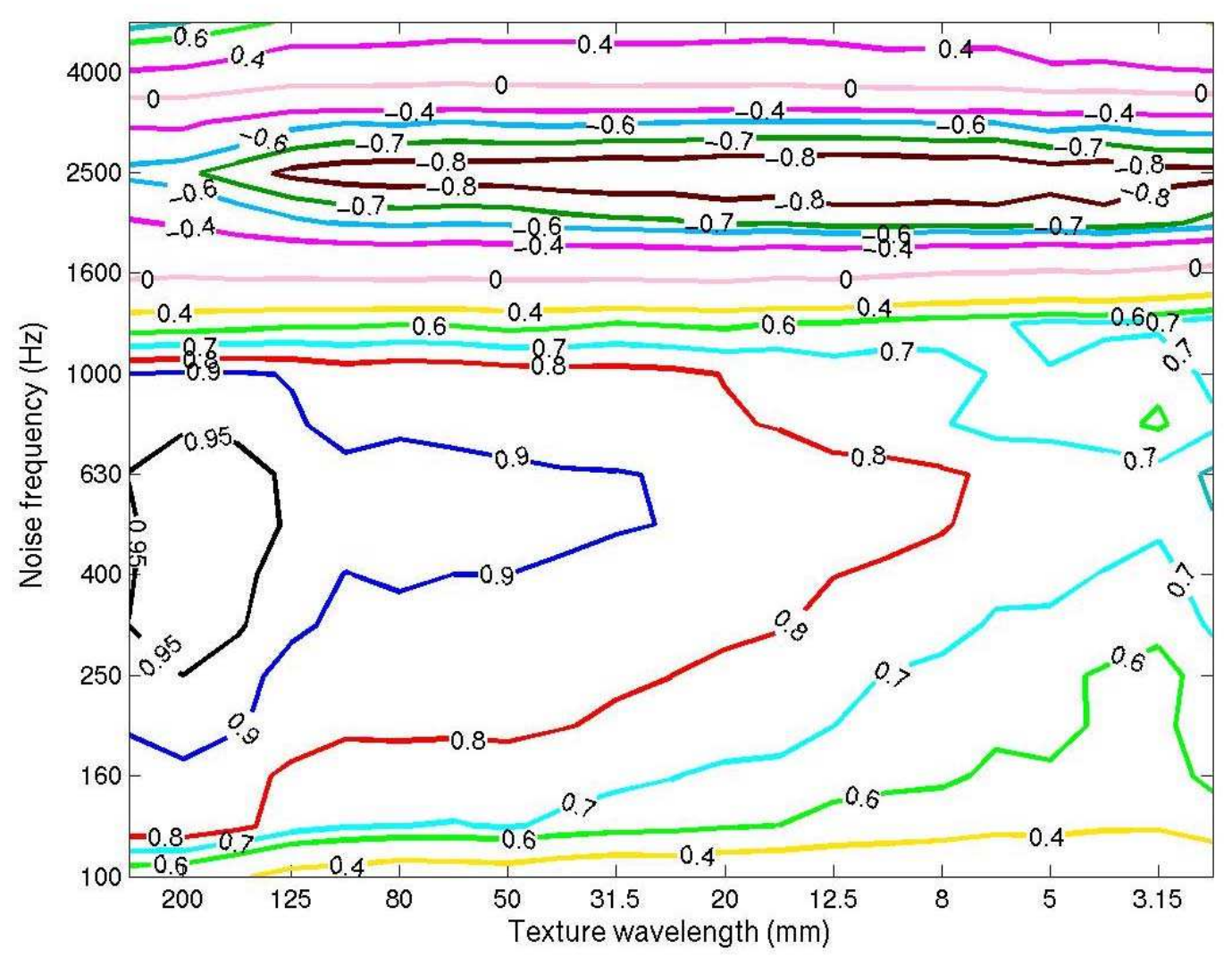

FIGURE 5 Contour lines of correlation coefficient between noise level $(90 \mathrm{~km} / \mathrm{h})$ and texture level porous pavement excluded. 


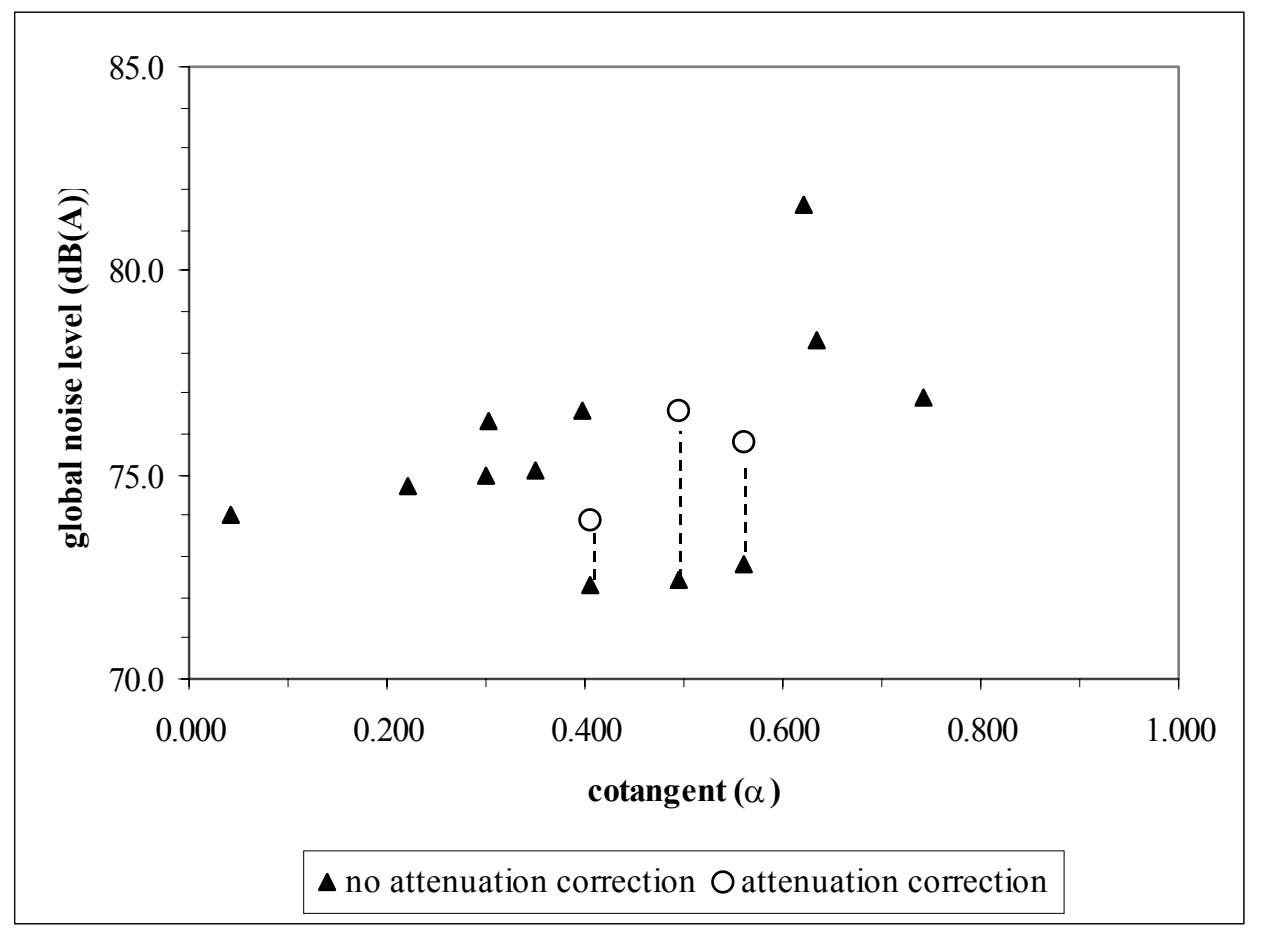

FIGURE 6 Relationship between indenter shape and noise. 


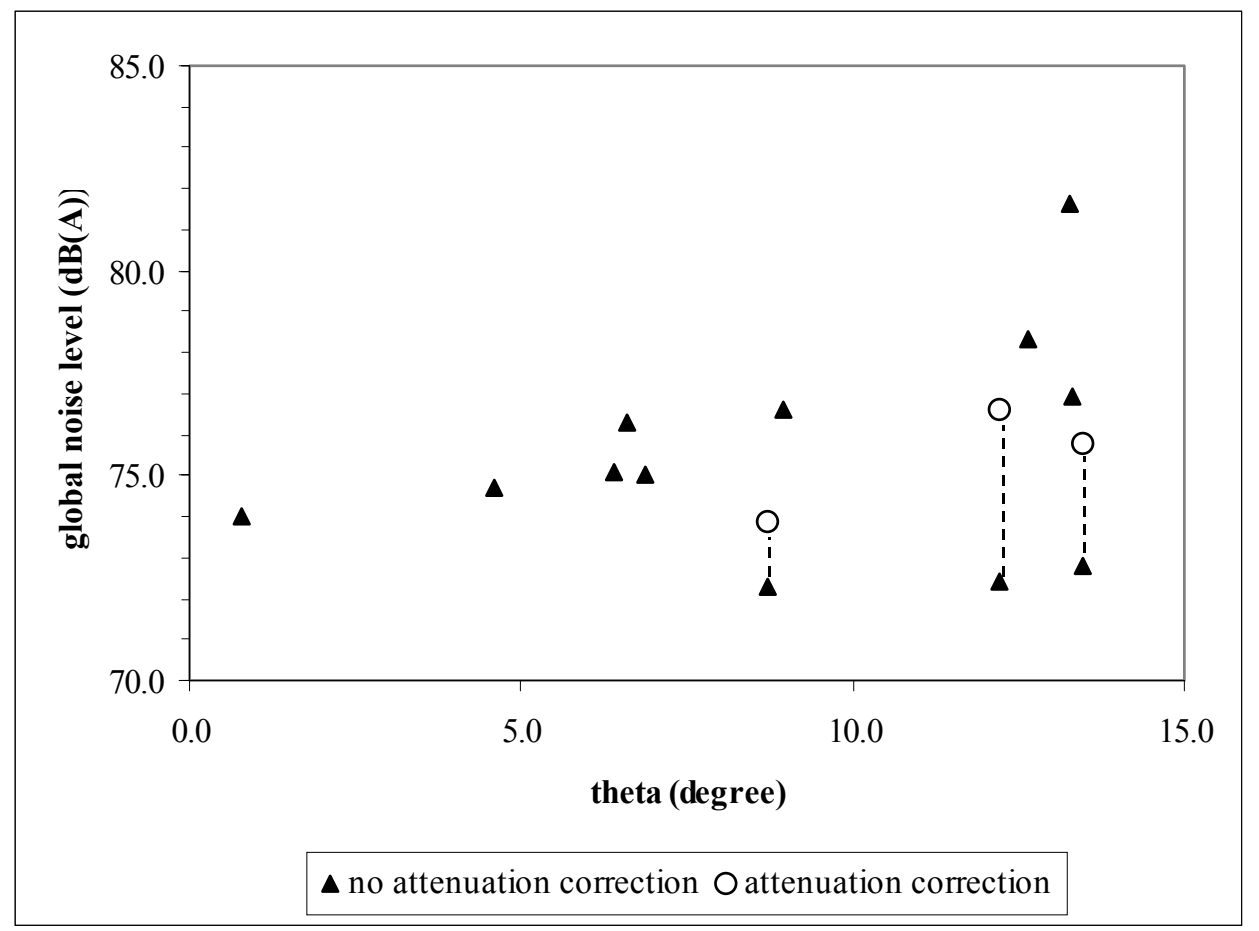

FIGURE 7 Relationship between indenter relief and noise. 


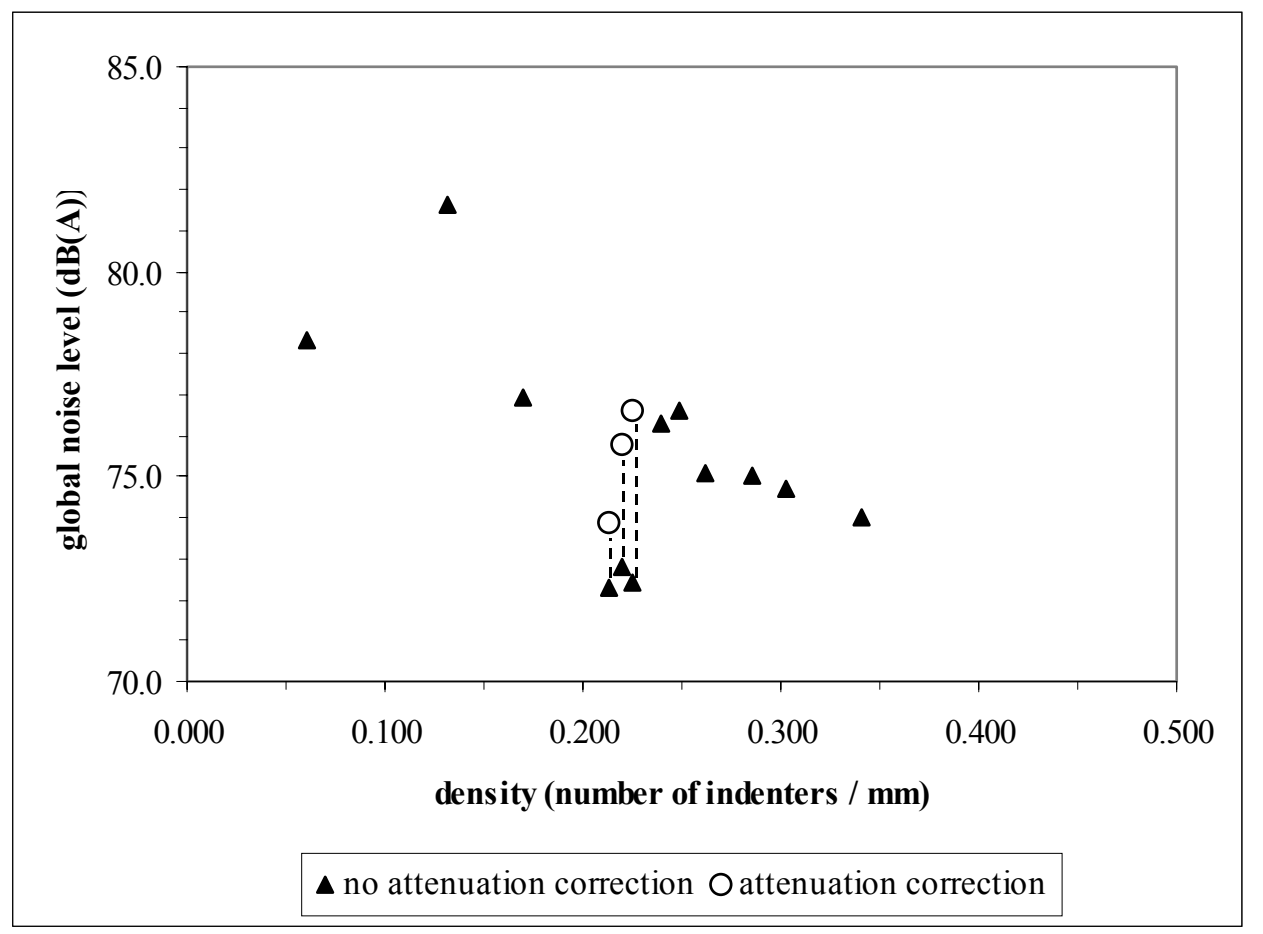

FIGURE 8 Relationship between indenter density and noise. 


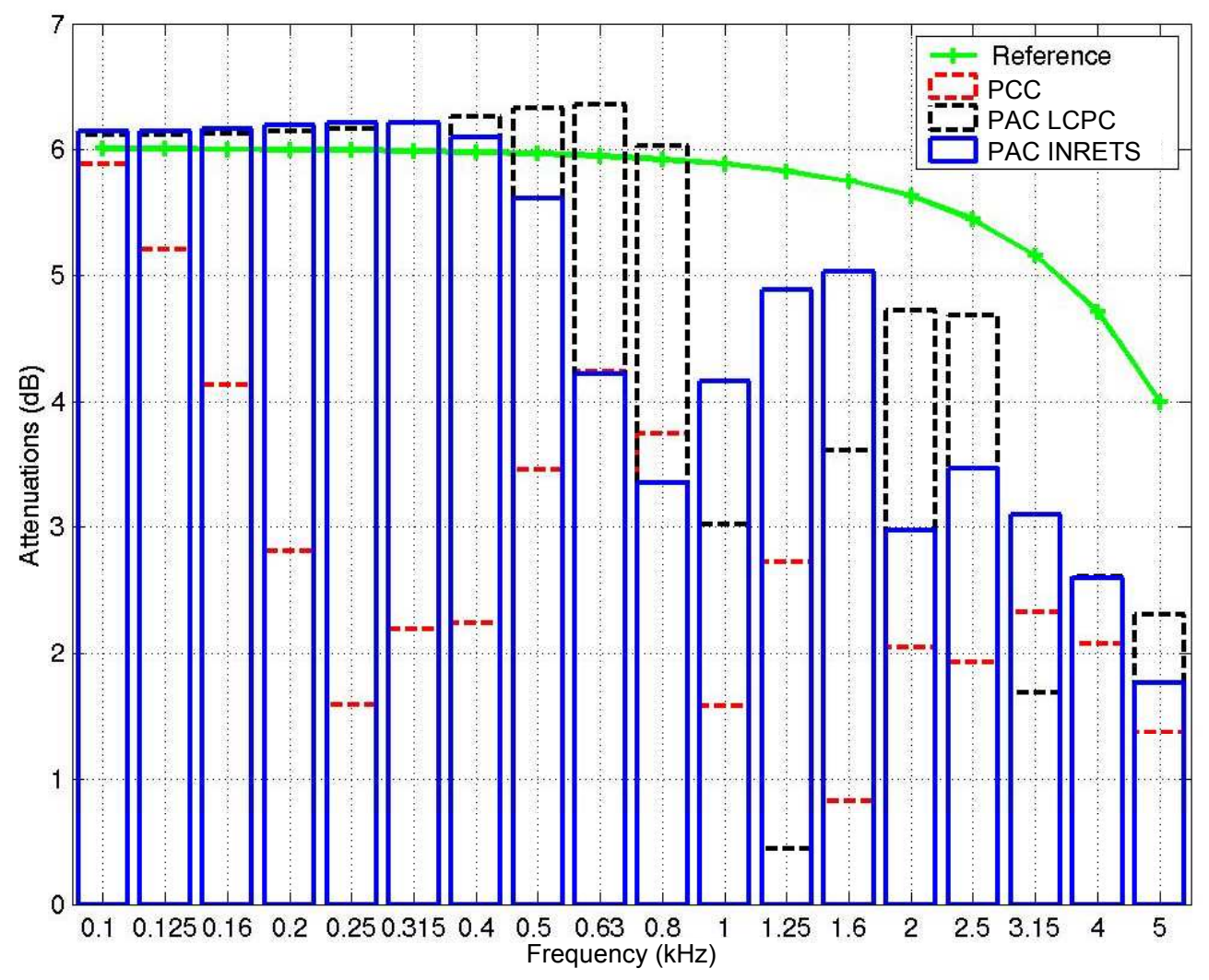

FIGURE 9 Calculated sound attenuation above porous surfaces (bars) and reflecting surface (curve) 


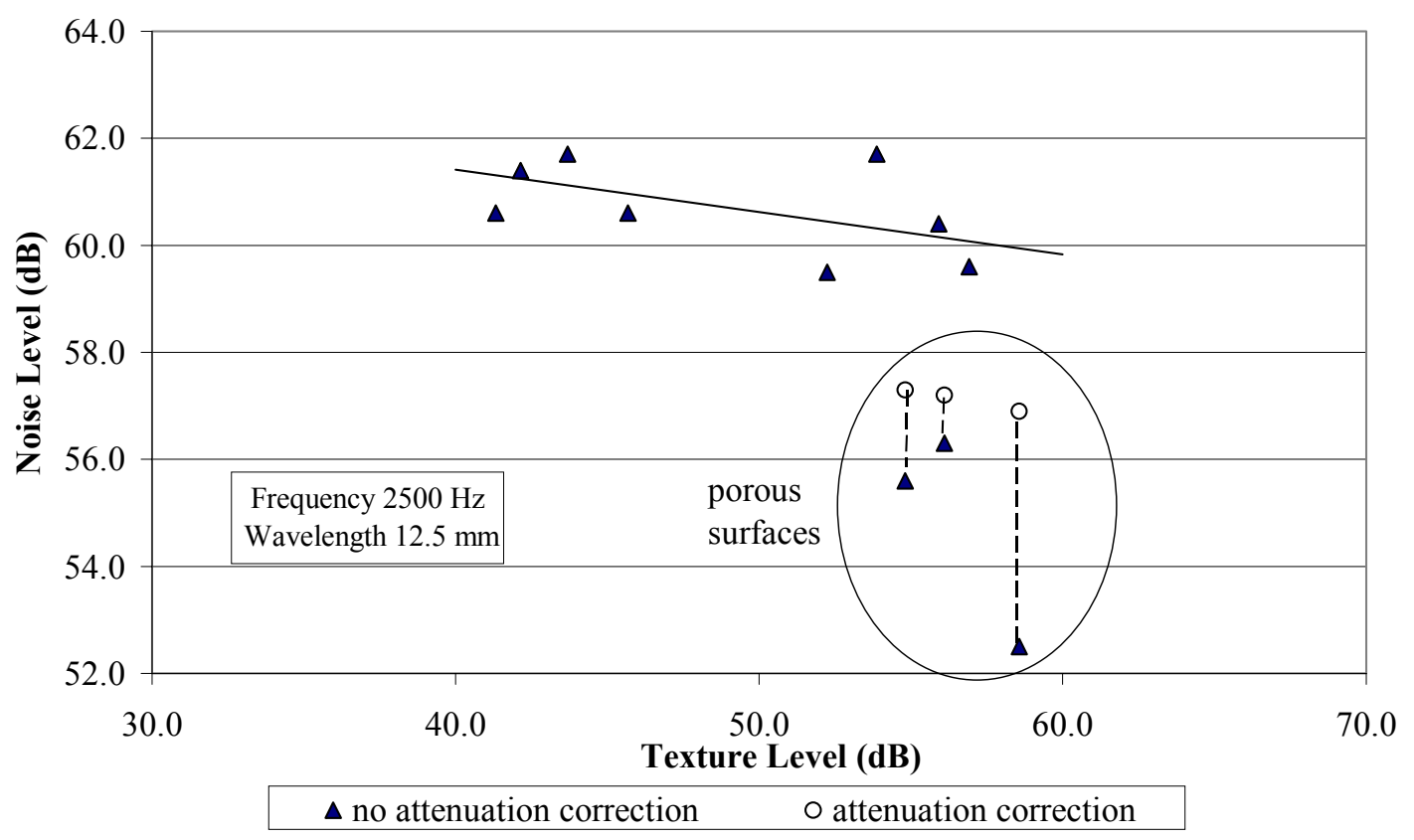

FIGURE 10 Correlation between noise and texture levels for third octave bands centered on frequency $2500 \mathrm{kHz}$ and wavelength $12.5 \mathrm{~mm}$ 


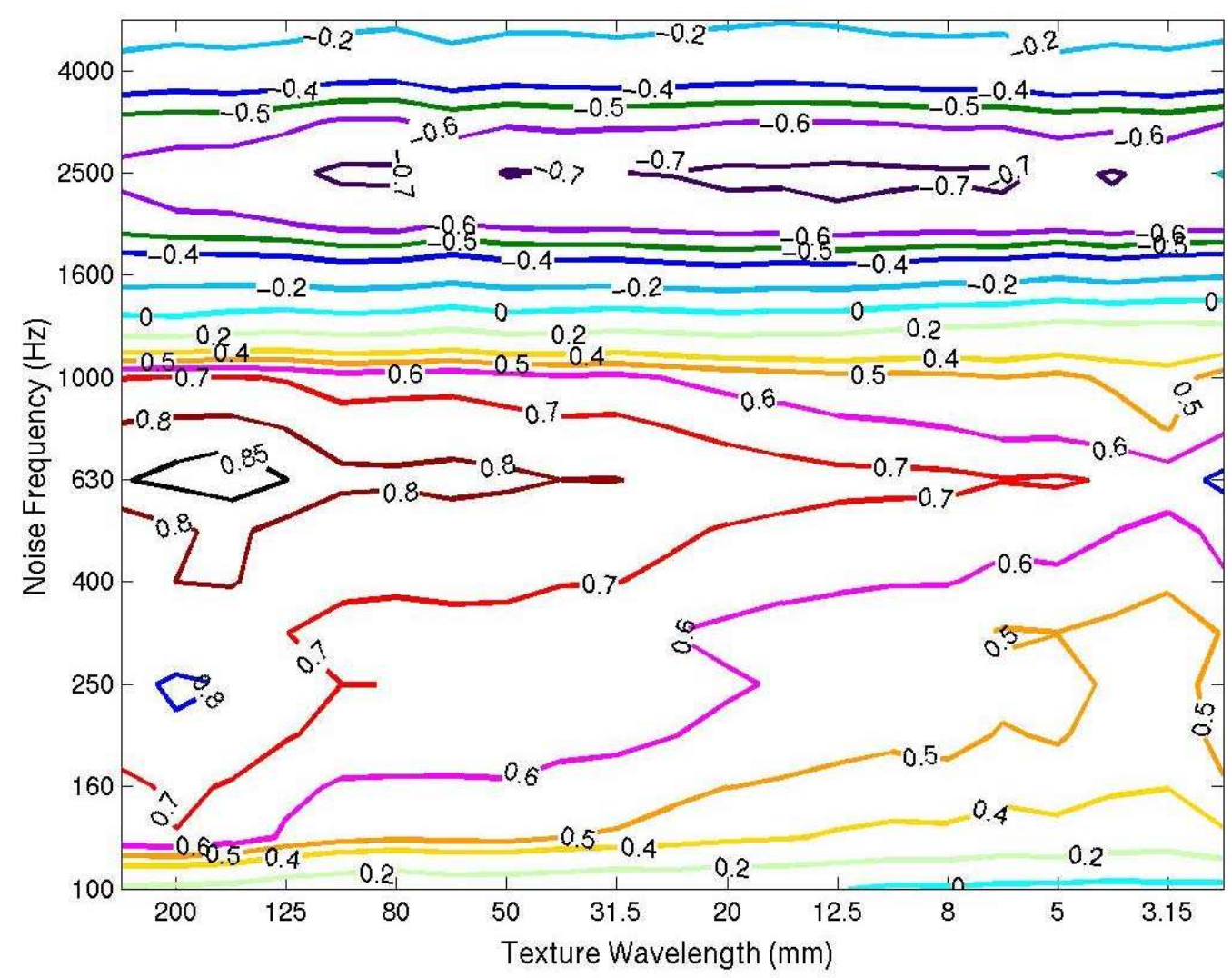

FIGURE 11 Contour lines of correlation coefficient between noise level and texture level - correction for porous pavements. 


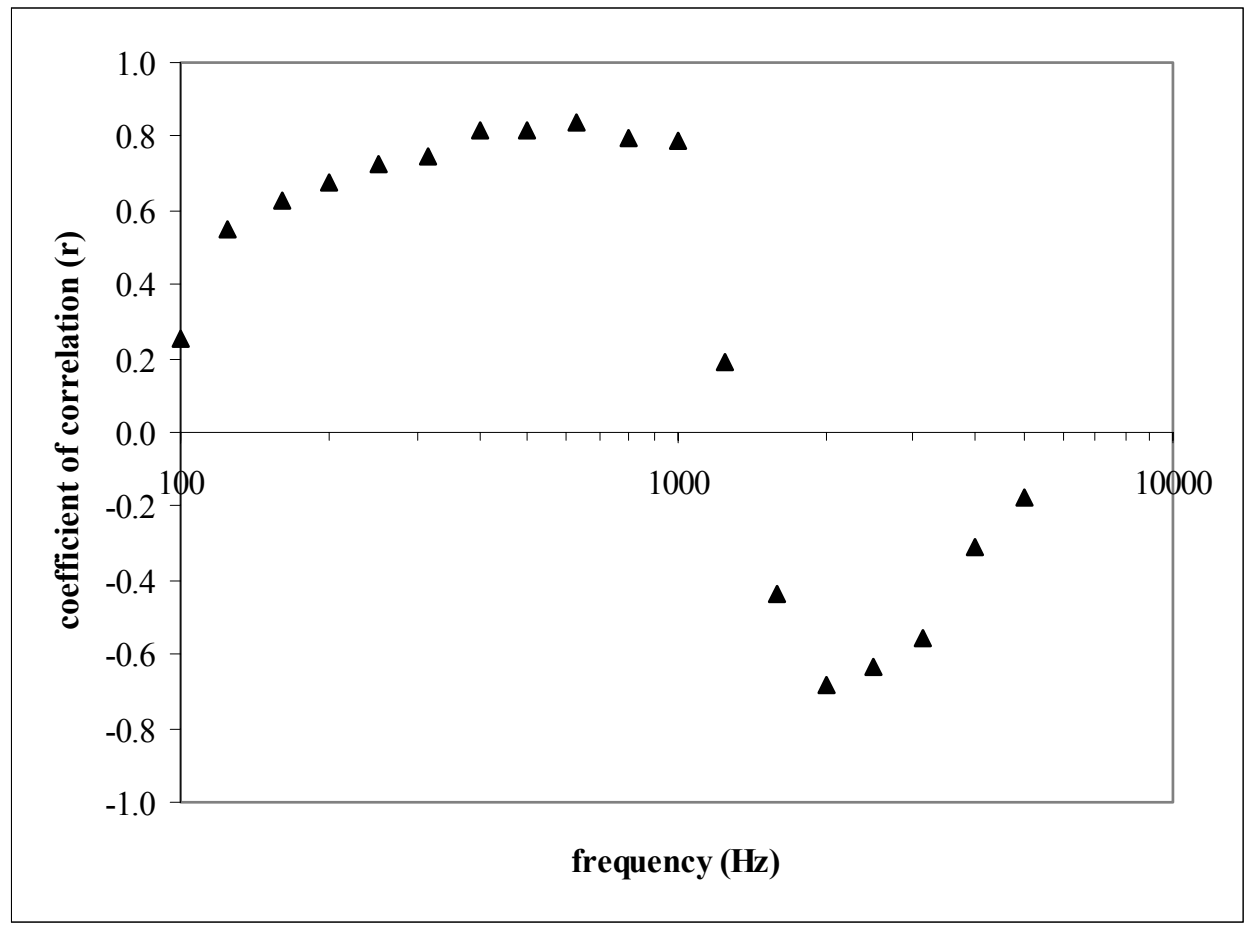

FIGURE 12 Variation of the coefficient of correlation between noise and texture with noise frequency. 
TABLE 1 Correlation Between Global Noise Level and Geometric Descriptors

\begin{tabular}{lll}
\cline { 2 - 3 } $\begin{array}{l}\text { Correlation between global } \\
\text { noise level and }\end{array}$ & $\begin{array}{l}\text { Without } \\
\text { attenuation } \\
\text { correction }\end{array}$ & $\begin{array}{l}\text { With attenuation } \\
\text { correction }\end{array}$ \\
\hline Cotangent $(\alpha)$ & 0.41 & 0.67 \\
$\theta$ & 0.31 & 0.67 \\
Density & -0.57 & -0.75 \\
\hline
\end{tabular}


TABLE 2 Results from Linear Regression on $3^{\text {rd }}$ Octave Band Noise Levels and Cotangent $(\alpha)$ Values Noise Level $(\mathrm{dB}(\mathrm{A}))=\mathrm{A} \times$ Cotangent $(\alpha)+\mathrm{B}$

\begin{tabular}{llll}
\hline $3^{\text {rd }}$ Octave Band Frequency & A & B & r-squared \\
$(\mathrm{Hz})$ & & & \\
\hline 100 & 2.34 & 68.2 & 0.06 \\
125 & 9.99 & 56.5 & 0.30 \\
160 & 11.23 & 55.2 & 0.40 \\
200 & 11.10 & 56.1 & 0.45 \\
250 & 12.70 & 56.2 & 0.52 \\
315 & 15.86 & 55.6 & 0.56 \\
400 & 17.64 & 53.2 & 0.67 \\
500 & 18.65 & 53.0 & 0.67 \\
630 & 20.69 & 56.6 & 0.70 \\
800 & 18.28 & 59.0 & 0.64 \\
1000 & 12.13 & 63.4 & 0.62 \\
1250 & 2.05 & 67.5 & 0.04 \\
1600 & -4.26 & 66.7 & 0.19 \\
2000 & -5.68 & 65.0 & 0.47 \\
2500 & -6.41 & 62.9 & 0.41 \\
3150 & -4.77 & 59.8 & 0.31 \\
4000 & -1.99 & 58.2 & 0.10 \\
5000 & -1.38 & 54.7 & 0.03 \\
\hline
\end{tabular}

